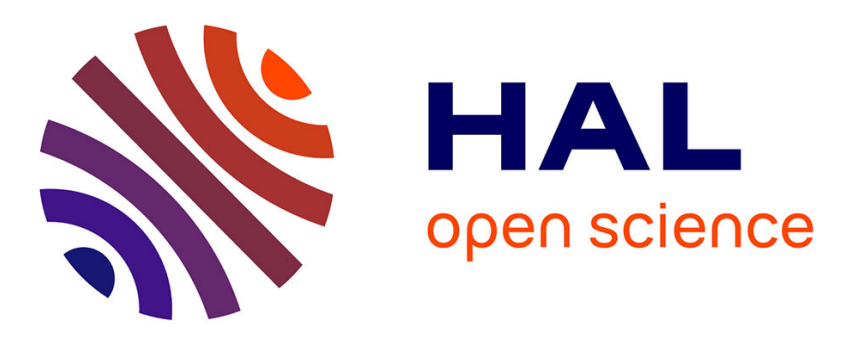

\title{
Dynamics of Air Avalanches in the Access Pit of an Underground Quarry
}

F Perrier, P Morat, J.-L Le Mouël

\section{To cite this version:}

F Perrier, P Morat, J.-L Le Mouël. Dynamics of Air Avalanches in the Access Pit of an Underground Quarry. Physical Review Letters, 2002, 89, pp.134501. 10.1103/PhysRevLett.89.134501 . insu01298305

\section{HAL Id: insu-01298305 \\ https://hal-insu.archives-ouvertes.fr/insu-01298305}

Submitted on 5 Apr 2016

HAL is a multi-disciplinary open access archive for the deposit and dissemination of scientific research documents, whether they are published or not. The documents may come from teaching and research institutions in France or abroad, or from public or private research centers.
L'archive ouverte pluridisciplinaire HAL, est destinée au dépôt et à la diffusion de documents scientifiques de niveau recherche, publiés ou non, émanant des établissements d'enseignement et de recherche français ou étrangers, des laboratoires publics ou privés. 


\title{
Dynamics of Air Avalanches in the Access Pit of an Underground Quarry
}

\author{
F. Perrier, ${ }^{1, *}$ P. Morat, ${ }^{2}$ and J.-L. Le Mouël ${ }^{2}$ \\ ${ }^{1}$ Département Analyse, Surveillance, Environnement, Commissariat à l'Energie Atomique, B.P. 12, \\ 91680 Bruyères-le-Châtel, France \\ ${ }^{2}$ Laboratoire de Géomagnétisme, Institut de Physique du Globe, 4, Place Jussieu, 75005 Paris, France
}

(Received 4 April 2002; published 9 September 2002)

\begin{abstract}
Temperature measurements have been performed in the vertical access pit of an underground quarry. During autumn, air avalanches induce an initial thermal feedback and a stationary mixing state characterized by spatially coherent broad-band fluctuations with a standard deviation of about $0.2^{\circ} \mathrm{C}$, linearly increasing with the inside-minus-outside temperature difference. Phase changes of water are shown to contribute to the onset condition, the feedback, and the stationary mixing state. This experiment may give insight on turbulent thermal and compositional convection with nonadiabatic boundaries.
\end{abstract}

DOI: 10.1103/PhysRevLett.89.134501

PACS numbers: $51.20 .+\mathrm{d}, 47.27 .-\mathrm{i}$

Laboratory experiments studying heat transport in fluids through turbulent buoyant plumes have revealed many unexpected features [1,2] such as anomalous scaling, intermittent bursts, or the onset of oscillations above a critical Rayleigh number [3]. In a natural environment, coherent temperature and humidity oscillations have been observed at the rock-atmosphere interface in an underground quarry [4]. Underground sites, which are thermodynamically stable, are particularly interesting in order to study the nonlinear dynamics of air at intermediate scales, from about $1 \mathrm{~m}$ to several hundred meters. Such sites also offer a unique opportunity to study open systems with the additional effects of time dependent flows, nonadiabatic boundaries [5], and phase changes. Indeed, one important feature of natural caves or underground quarries is the pervading presence of water. Here we report observations associated with cold avalanches in the air of the access pit of an underground quarry located in Vincennes, near Paris.

The abandoned "La Brasserie" limestone quarry [6] consists of pillars and rooms having an average height of $2.4 \mathrm{~m}$ and spread over an area of $32000 \mathrm{~m}^{2}$, located about $18 \mathrm{~m}$ below the ground surface. It has an average temperature of $12.7^{\circ} \mathrm{C}$, with variations over one year remaining within $0.12{ }^{\circ} \mathrm{C}$ in the atmosphere and within $0.05^{\circ} \mathrm{C}$ in the rock. The relative humidity of the atmosphere is high, with values compatible with saturation given the measurement accuracy. The quarry is connected to the outside by a single large access pit with a diameter of $4.6 \mathrm{~m}$ (Fig. 1). The upper part of the pit reaches in a building, but broken panes in windows with a surface area of about $2.3 \mathrm{~m}^{2}$ allow air exchange.

With the simple geometry of the access pit (Fig. 1), two regimes are expected. As long as the outside temperature remains higher than the average temperature of the quarry, the atmosphere of the pit and of the quarry remains water saturated and stable, at least for a stable atmospheric pressure. When the outside air temperature is smaller than $12.7^{\circ} \mathrm{C}$, however, a natural ventilation mixing is expected [5]. This simple mechanism is complicated by the fact that the quarry air and the outside air have different humidity, and by the fact that water and heat can be exchanged with the walls.

In order to study this natural ventilation, a first set of ten thermistors were installed at the beginning of 2000 in the pit (Fig. 1) near the metallic staircase. These thermistors have a diameter of $5 \mathrm{~mm}$, a length of $30 \mathrm{~mm}$, and a sensitivity of about $135 \Omega /{ }^{\circ} \mathrm{C}$ at $12{ }^{\circ} \mathrm{C}$ [7]. They were not calibrated individually but were sorted to have similar characteristics in the laboratory so that differences in their relative calibration can be neglected in the present experiment. A common average calibration was applied to convert resistance values to degrees. Given their size, these thermistors have a thermal response time of the order of $30 \mathrm{~s}$, and temperatures are recorded with a sampling time of $1 \mathrm{~min}$.

Typical temperature records obtained during the transition period between summer and winter are shown in Fig. 2. Two regimes are observed. The first regime (summer regime) is characterized by a stable temperature at a depth larger than $10 \mathrm{~m}$ in the pit (sensors TP1 to TP3). The second regime (winter regime) is characterized by a decreased temperature in the pit, particularly for sensors TP1 to TP3. Simultaneously, fluctuations of about $0.5^{\circ} \mathrm{C}$ peak to peak appear systematically on all sensors. This regime appears when the temperature in the upper part of the pit (sensor TP10), which in a first approximation reflects the outside air temperature, drops below some threshold close to the average temperature of the quarry. This winter regime can therefore be associated with cold air avalanches in the pit.

This is further illustrated in Fig. 3 where all data from March 2000 to September 2001 have been incorporated. In this figure, average temperature values of sensors TP1, TP4, and TP8, obtained over 2-hour sections, are displayed as a function of the corresponding average value 


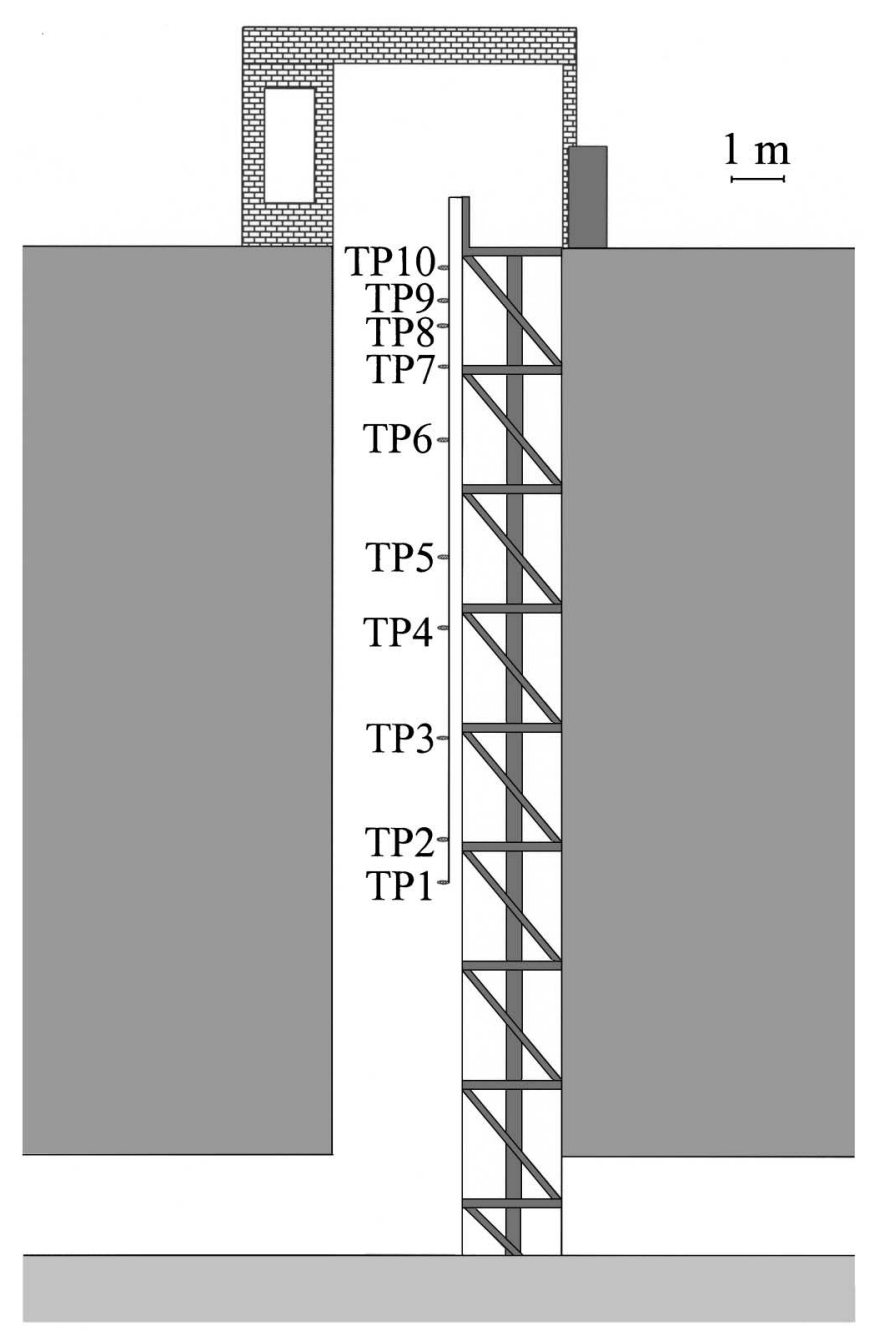

FIG. 1. Access pit of the Vincennes quarry.

for sensor TP10. As long as the average temperature of sensor TP10 is larger than $12.7^{\circ} \mathrm{C}$, the temperature of sensor TP1 remains extremely stable. When the average temperature of sensor TP10 is lower than $12.7^{\circ} \mathrm{C}$, the temperatures of TP1 and TP4 drop and are similar, indicating an efficient vertical mixing. In Fig. 3, the standard deviation of temperature TP1 is also shown. The amplitude of the fluctuations also has a sharp transition at $12.7^{\circ} \mathrm{C}$ and is increasing linearly when the temperature difference between the equilibrium quarry temperature and the outside temperature is increasing.

The temperature fluctuations have a similar peak to peak amplitude from TP1 to TP10 (Fig. 2). In contrast to the oscillations observed in the RB laboratory experiments $[2,3]$, they do not show resonant frequencies. The spatial coherence of the fluctuations can be characterized by the coherency matrix $c_{i j}$ defined by

$$
c_{i j}=\frac{\sum_{k} T_{i}(k) T_{j}(k)}{\sqrt{\sum_{k} T_{i}(k)^{2}} \sqrt{\sum_{k} T_{j}(k)^{2}}},
$$

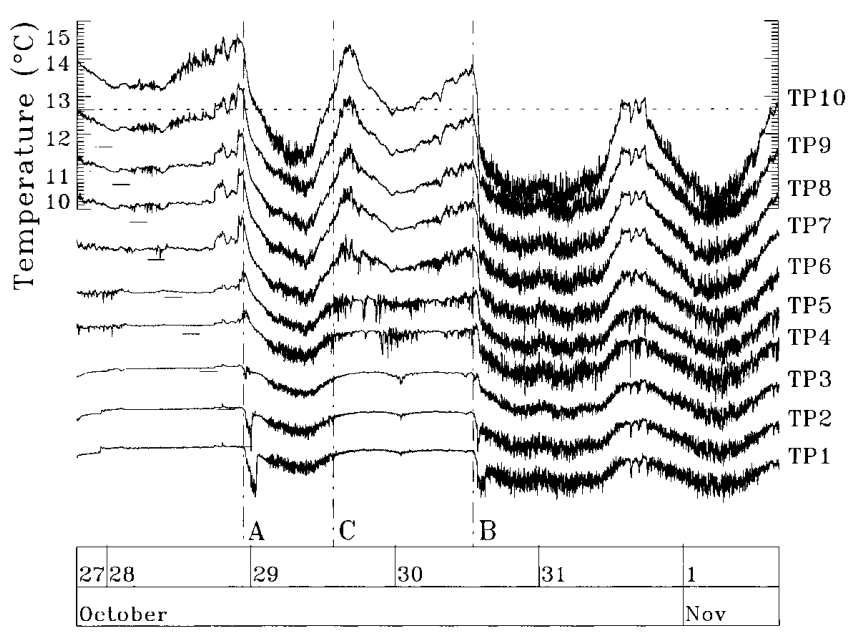

FIG. 2. Temperature time series from 27 October to 1 November 2000. The absolute temperature scale is indicated for sensor TP10. Each track is then shifted keeping the same amplitude scale. The $12.7^{\circ} \mathrm{C}$ reference for each track is indicated by short staggered horizontal lines.

where $T_{i}(k)$ refers to a given temperature time series for sensor TPi and $T_{j}(k)$ the corresponding time series for sensor TPj. In order to isolate the fluctuations, the slow temperature variations are approximated by a polynomial fit and subtracted from the measured time series. A typical spatial dependence of the sensor to sensor coherency is shown in Fig. 4. The coherency is rather large $(>0.7)$ for a short distance and is decreasing smoothly with distance. A typical coherence length of about $4 \mathrm{~m}$ is observed, of the order of the pit diameter. The region between the surface and a depth of the order of 3 to $4 \mathrm{~m}$ seems to have a difference behavior, with a larger coherency over a short distance. This is probably due to the close distance to the air exchange windows or an effect of wind. The

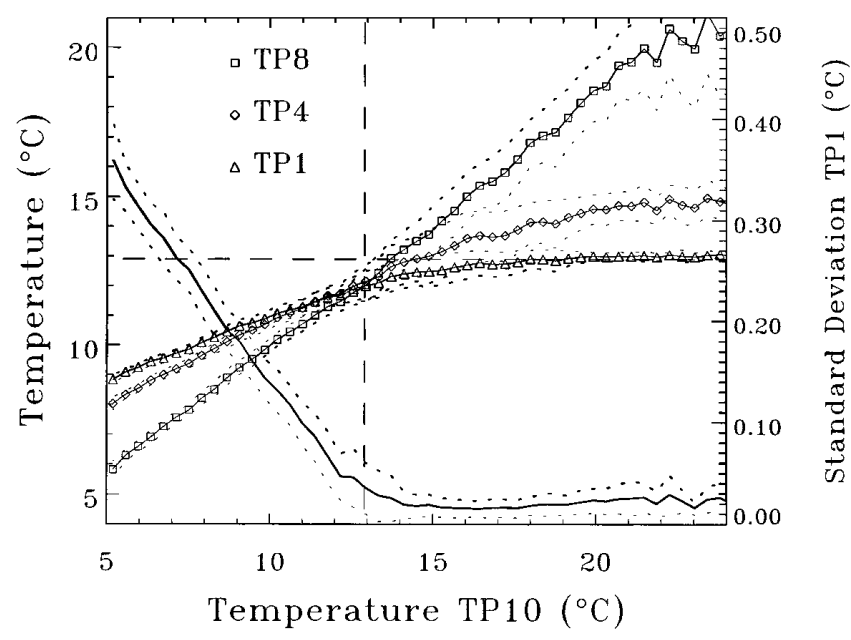

FIG. 3. Mean temperature of sensors TP1, TP4, and TP8 (left scale) and standard deviation of sensor TP1 (right scale) versus mean temperature of sensor TP10. 


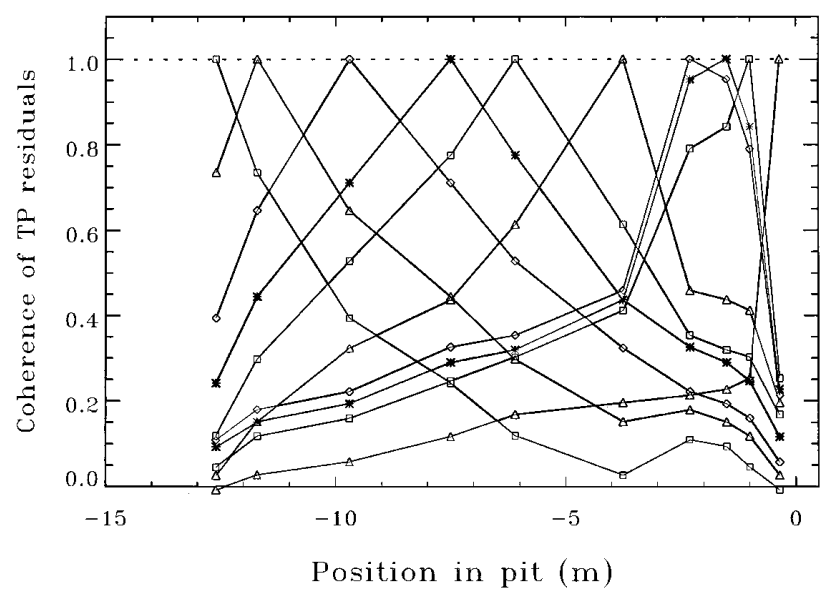

FIG. 4. Coherence of temperature residuals as a function of position in the pit. $C_{i j}$ is depicted at position $z_{j}$ on the line which has a value of 1 at $z_{i}$. Data correspond to 6 p.m., 31 October to 10 a.m., 1 November 2000.

pattern of correlation displayed in Fig. 4 does not depend on the particular time series chosen. Additional experiments also indicated that the horizontal coherency of the temperature fluctuations during the winter regime is larger than 0.7 over the whole diameter of the pit. The large vertical coherence length and this strong coherence over a horizontal section of the pit reflect an efficient global organization of the air dynamics.

Such broad-band coherent temperature fluctuations are intriguing. Pressure variations can induce temperature fluctuations that are coherent over large distances but amplitudes are smaller than $0.05^{\circ} \mathrm{C}$ [7]. The temperature fluctuations must be associated with a random vigorous stirring associated with the falling cold plumes. To understand the underlying processes, two important additional features of the reversible transition between the two regimes have to be pointed out in Fig. 2. First, a reproducible feedback response follows the initiation of the air flow. This is especially noteworthy for sensor TP1 for which the initial temperature drop ( $A$ and $B$ in Fig. 2$)$ is compensated after about $1 \mathrm{~h}$ to reach a larger intermediate stationary temperature. Second, the cold avalanches are not initiated or terminated when the temperature TP10 is equal to the equilibrium quarry temperature, but at a slightly higher temperature: $14.3^{\circ} \mathrm{C}$ for transition $A, 13.8^{\circ} \mathrm{C}$ for transition $B$, and $13.0^{\circ} \mathrm{C}$ for transition $C$ (Fig. 2).

The latter fact can be understood readily. Indeed, the density $\rho_{a}$ of air containing a concentration $c_{a}^{w}$ of water (expressed in mass of water by air volume) is given by

$$
\frac{\rho_{a}-\rho_{a}^{d}}{\rho_{a}^{d}}=-c_{a}^{w} V_{a}^{M} \frac{M_{a}-M_{w}}{M_{w} M_{a}}=-R H_{a} \frac{p_{v}}{p} \frac{M_{a}-M_{w}}{M_{a}},
$$

where $\rho_{a}^{d}$ is the density of dry air $\left(1.2 \mathrm{Kg} / \mathrm{m}^{3}\right.$ at $\left.12{ }^{\circ} \mathrm{C}\right)$,
$V_{a}^{M}$ the molar volume of air $\left(0.023 \mathrm{~m}^{3}\right.$ at $\left.12{ }^{\circ} \mathrm{C}\right), M_{w}$ the molar mass of water $(0.018 \mathrm{Kg}), M_{a}$ the molar mass of dry air $(0.029 \mathrm{Kg}), R H_{a}$ the relative humidity, $p$ the atmospheric pressure, and $p_{v}$ the saturated water pressure $\left(1.4 \mathrm{kPa}\right.$ at $\left.12^{\circ} \mathrm{C}\right)$. According to Eq. (2), the quarry air of temperature $T_{a}$ and saturated with water $\left(R H_{a}=1\right)$ has the same density as the outside air of temperature $T_{e}$ and relative humidity $R H_{e}=0.5$ when $T_{e}-T_{a}=$ $0.75^{\circ} \mathrm{C}$, which is in agreement with the observations.

Water also has an important contribution to the observed dynamical behavior. Indeed, the cold avalanches falling in the pit contain dry air that will interact with the moist walls and the humid quarry air, and evaporation from the walls must occur and potentially induce a thermal feedback response. This boundary controlled effect could ensure large horizontal coherence and vertical homogeneity of the order of the pit diameter. Such a mechanism can actually be illustrated in a simple model.

Consider the quarry pit as a homogeneous box of volume $V_{a}\left(327 \mathrm{~m}^{3}\right)$ with temperature $T_{a}$ and water content $c_{a}^{w}$. This box is in contact with an external reservoir of temperature $T_{e}$ and water content $c_{e}^{w}$, then natural ventilation [8] occurs if the buoyancy defined by

$$
g^{\prime}=g\left(\frac{T_{a}-T_{e}}{T_{0}}+\left(c_{a}^{w}-c_{e}^{w}\right) V_{a}^{M} \frac{M_{a}-M_{w}}{M_{w} M_{a}}\right),
$$

where $T_{0}$ is the absolute equilibrium temperature of the quarry and $g$ is the acceleration of gravity, is positive. By similarity with other flows [5], the mixing flow rate can be estimated as $C_{D} A \sqrt{g^{\prime} H}$ where $A$ is the area of the opening $\left(2.3 \mathrm{~m}^{2}\right)$ and $H$ is the height of the box. The discharge coefficient $C_{D}$ takes into account the shape of the opening and a value of 0.6 is used [5,8]. Assuming $T_{a}-T_{e}=1{ }^{\circ} \mathrm{C}$ and $R H_{a}=R H_{e}=0$, the flow rate amounts to $1.2 \mathrm{~m}^{3} / \mathrm{s}$, corresponding to velocities of $15 \mathrm{~cm} / \mathrm{s}$, assuming that down-going and up-going flows each share half of the pit section $\left(16.3 \mathrm{~m}^{2}\right)$. If a cold avalanche falls down the pit with this velocity, then the transit time of the perturbation from TP10 to TP1 is about $80 \mathrm{~s}$, compatible with the observation (Fig. 2).

The time evolution of the water content $c_{a}^{w}$ can then be described by an equation with a mixing term and a relaxation term:

$$
\frac{d c_{a}^{w}}{d t}=-\alpha g^{\prime 1 / 2}\left(c_{a}^{w}-c_{e}^{w}\right)-\frac{1}{\tau_{w}}\left(c_{a}^{w}-c_{s}^{w}\right),
$$

where $\alpha=C_{D} A \sqrt{H} / V_{a}, c_{s}^{w}$ is some reference water content at the wall and $\tau_{w}$ is a relaxation time for water exchange. Here we assume that $c_{s}^{w}$ is the water content of the atmosphere at saturation at the wall temperature $T_{0}$. Similarly, the air temperature in the box is described by

$$
\frac{d T_{a}}{d t}=-\alpha g^{1 / 2}\left(T_{a}-T_{e}\right)-\frac{1}{\tau_{0}}\left(T_{a}-T_{0}\right)+\beta\left(c_{a}^{w}-c_{s}^{w}\right),
$$


where $\tau_{0}$ is a thermal relaxation term [7]. The last term corresponds to the latent heat associated with the water exchange and $\beta=L / \rho_{a}^{d} c_{a} \tau_{w}$, where $c_{a}$ is the specific heat of dry air $\left(10^{3} \mathrm{~J} \mathrm{~kg}^{-1} \mathrm{~K}^{-1}\right)$ and $L$ the latent heat of water $\left(2.5 \times 10^{6} \mathrm{~J} / \mathrm{kg}^{-1}\right)$. The relaxation times $\tau_{w}$ and $\tau_{0}$ do not need to be identical. Actually, general considerations [9] suggest that $\tau_{w} / \tau_{0}$ is scaling as $1 / L e^{2 / 3}$ where $L e$ is the Lewis number $(\approx 1.2)$. We shall therefore concentrate on the case $\tau_{w}<\tau_{0}$.

The coupled equations (4) and (5) describe our simplified system. When $g^{\prime}<0$, then no mixing is present, and the system is described by the same equations, putting $\alpha=0$. In this case, the coupled equations predict a relaxation of $T_{a}$ and $c_{a}^{w}$ towards the equilibrium values $T_{0}$ and $c_{s}^{w}$. In the general case, for given time series $T_{e}(t)$ and $c_{e}^{w}(t)$, the resulting time series $T_{a}(t)$ and $c_{a}^{w}(t)$ can be calculated numerically. One example is shown in Fig. 5 assuming $\tau_{w}=15 \mathrm{~min}, \tau_{w} / \tau_{0}=0.3$, and $R H_{e}=0.4$ constant with time. The calculated air temperature has both a feedback response at the onset of the flow and an oscillatory behavior during the stationary phase.

This model does not claim to be a comprehensive representation of the quarry pit. In particular, the spectral content of the fluctuations remains to be understood. This model however supports the hypothesis that water, potentially, can be the physical parameter controlling the initial thermal feedback response and that it can also contribute to the large spatial organization of the thermal broad-band fluctuations. The fluctuations themselves probably result from turbulent swirling motions, which are, for example, observed when a colored salt solution is put in contact above a beaker of clear water. The side walls must play an important role in the spatial organization of the buoyant plumes, and therefore the dynamics could be significantly different in a free atmospheric column of air. Taking time sections of the order of $1 \mathrm{~h}$, the coherence of the fluctuations of TP1, TP2, and TP3 is increased if a positive delay of about $5 \mathrm{~s}$ for TP2 and about $27 \mathrm{~s}$ for TP3 is introduced with respect to TP1. These delays correspond to up-going velocities of about 10 and $17 \mathrm{~cm} / \mathrm{s}$, respectively. These velocity values are comparable with the value $15 \mathrm{~cm} / \mathrm{s}$ for the mixing velocity derived above. Most of the kinetic energy of the cold avalanches appears to be absorbed by the stationary fluctuations. The fact that the standard deviation of the fluctuations increases with the temperature gradient (Fig. 3) further suggests that the mixing flow due to the cold avalanches may lead to a reduced ventilation of the quarry. This blocking effect remains poorly quantified at this state.

This phenomenon is interesting to study in detail because it could be relevant in many practical applications of economic and cultural importance. In the context of underground waste repositories, natural ventilation is the

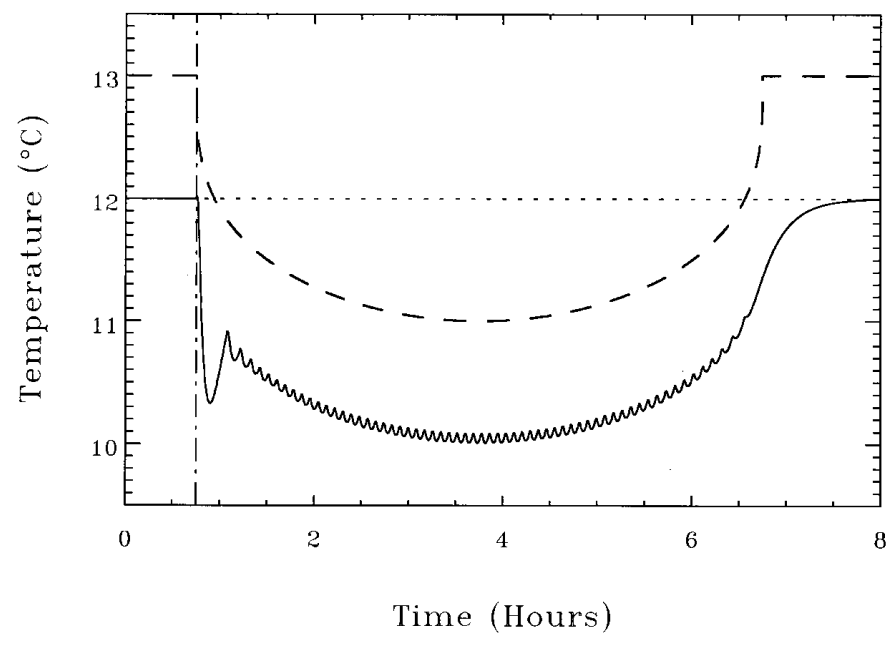

FIG. 5. Calculated temperature variations of the pit atmosphere in the simple box mixing model (dashed line: external temperature forcing).

main cooling process considered and the effects of water need to be understood. Combined heat and water exchange is also important in the context of the preservation of painted caves [10]. More generally, the observations in the Vincennes quarry pit may improve our understanding of combined thermal and compositional convection in fluids, which is an important key to the dynamics of the atmosphere and the interior of the Earth [11].

The authors thank the city of Paris for access to the Vincennes quarry. This work is IPGP Contribution No. 1834.

*Email address: perrier@dase.bruyeres.cea.fr

[1] S. Grossmann and D. Lohse, J. Fluid Mech. 407, 27 (2000).

[2] B. Castaing, G. Gunaratne, F. Heslot, L. Kadanoff, A. Libchaber, S. Thomae, X.-Z. Wu, S. Zaleski, and G. Zanetti, J. Fluid Mech. 204, 1 (1989).

[3] X.-L. Qiu and P. Tong, Phys. Rev. Lett. 87, 094501 (2001).

[4] P. Morat, J.-L. Le Mouël, J.-P. Poirier, and V. Kossobokov, C.R. Acad. Sci. Paris 328, 1 (1999).

[5] P. F. Linden, Annu. Rev. Fluid Mech. 31, 201 (1999).

[6] D. Moiriat, D. Obert, P. Pothérat, J. Bebien, and M. Laroche, Bull. Inf. Bass. Paris 37, 35 (2000).

[7] F. Perrier, P. Morat, and J.-L. Le Mouël, Earth Planet. Sci. Lett. 191, 145 (2001).

[8] P. Linden, G. Lane-Serff, and D. Smeed, J. Fluid Mech. 212, 309 (1990).

[9] T. Wigley and M. Brown, Boundary-Layer Meteorology 1, 300 (1971).

[10] A. Mangin, F. Bourges, and D. d'Hulst, C.R. Acad. Sci Paris 328, 295 (1999).

[11] S. Braginsky and P. Roberts, Geophys. Astrophys. Fluid Dyn. 79, 1 (1995). 